\title{
STUDIES OF THE CIRCULATION IN THREE CASES OF MORBUS CAERULEUS
}

\author{
By LUCIEN D'ÀUTREbande, W. R. MARShall and J. C. MEAKINS \\ (From the University Clinic, Department of Medicine, McGill University and \\ Royal Victoria Hospital, Montreal)
}

(Received for publication May 3, 1929)

\section{INTRODUCTION}

Studies on the anatomical peculiarities of congenital cardiac disease, with explanations of their embryonic development, have been comparatively common. Attention has been focused upon the numerous deviations from the normal which may occur as a developmental anomaly, but comparatively few studies have been made upon the functional disturbance of the circulation. Further, little or no attention has been paid to those means of physiological compensation and adaptation which would necessarily have to occur in order to maintain life. There has been the well-known differentiation into two broad classes,the cyanotic and non-cyanotic groups. The circulatory problems underlying the latter are but little different from those which occur in acquired cardiac disease. On the other hand, in Morbus Caeruleus (the cyanotic type of a case) a number of questions of great physiological importance arise. The present communication deals with three such cases all of which have been studied in more or less complete detail.

\section{MATERIAL}

Case no. $1, W . R$. Came under observation at the age of twelve years, giving a history of having suffered from shortness of breath, weakness, and blueness of the hands and face since infancy. On attempting exercise he could walk only a few feet before the cyanosis became intense, and persistence in the effort produced unconsciousness.

On physical examination he was a poorly developed, thin, male child, with pronounced cyanosis of the hands, ears, and mucous membranes. There was pronounced clubbing of the fingers and toes. The chest was prominent and rachitic, the venules of the upper thorax were quite distinct. The cardiac apex beat was 
palpable in the fifth left interspace just beyond the nipple line. On percussion the cardiac dullness was $3 \mathrm{~cm}$. to the right and 10 to the left of the mid-sternal line. On auscultation the sounds were loud; the first sound at the apex was re-duplicated

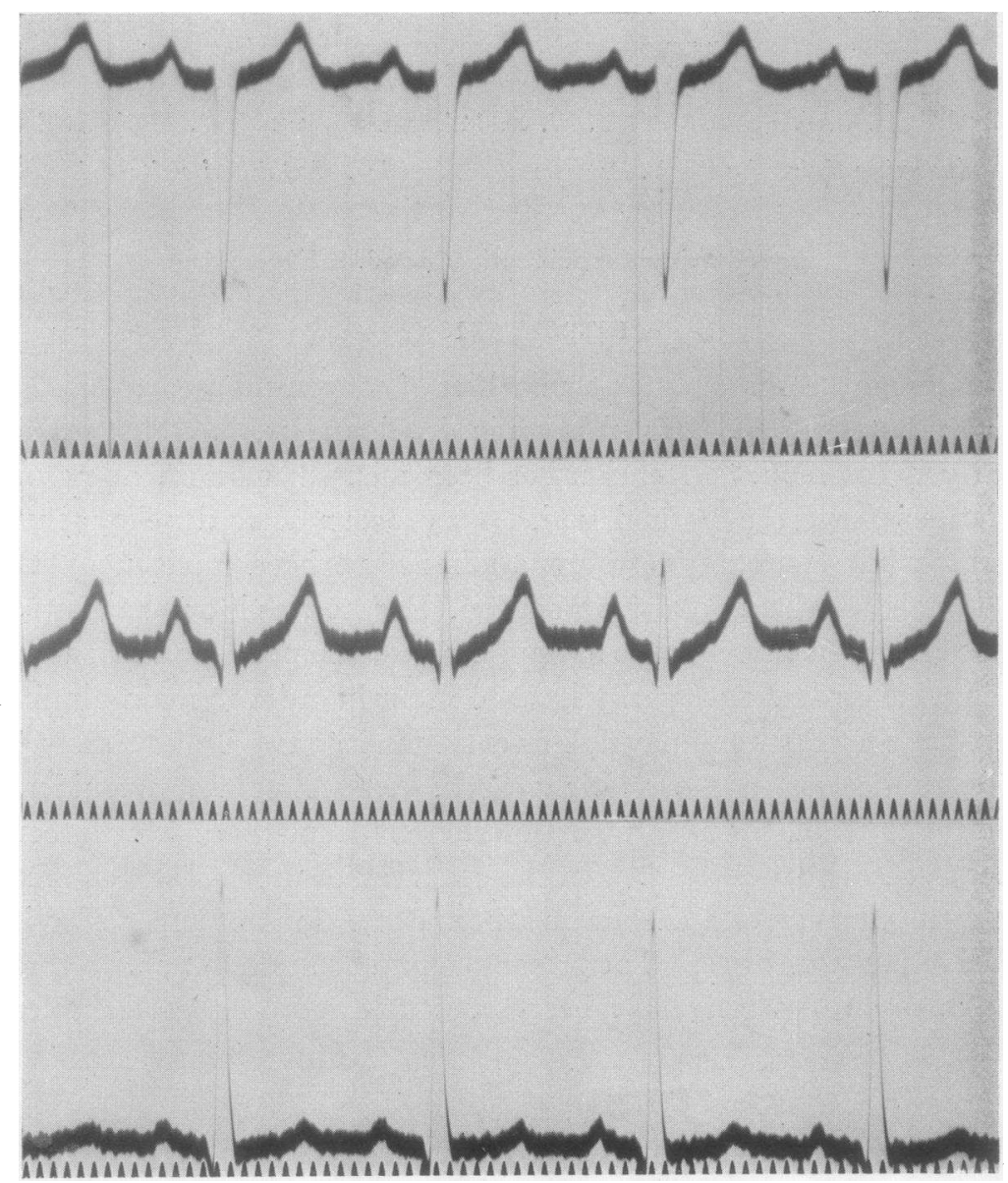

Fig. 1. Regular Rhythm. A-V Conduction Normal. Right-sided Preponderance, of Congenital Type and High Voltage. Intraventricular and Intra-Auricular Conduction Time Normal

$$
1 \mathrm{c} . \mathrm{m} .=1 \mathrm{~m} . \mathrm{v} \text {. }
$$

but there were no murmurs audible. The pulse rate was 118 , and the systolic blood pressure was $138 \mathrm{~mm}$. An electrocardiograph showed a right-sided preponderance (fig. 1). Examination of the blood showed the erythrocytes to num- 
ber $8,500,000$; haemoglobin 175 per cent. The ratio between the plasma and corpuscles was found by the haematocrit to be corpuscles 68.5 per cent, plasma 30.5 per cent.

He died suddenly on November 11, 1922. The post mortem revealed the following findings. The whole body, and particularly the hands and face were deeply cyanosed. On incision the blood was dark and almost too viscid to flow. The lungs showed a small amount of oedema and emphysema. The liver was enlarged, congested and fatty, while the spleen measured $12 \frac{1}{2} \times 7 \frac{1}{2} \times 5 \mathrm{~cm}$., was firm and had the appearance of chronic congestion. The mesenteric glands were enlarged. The heart was enlarged in all directions, especially the right auricle and ventricle. There was a fibrous cord representing the ductus arteriosus. The right auricle was distended and on opening it there was present a well-marked Eustachian valve and a slit-like and definitely patent foramen ovale. The wall of the right ventricle was extremely hypertrophied, being twice as thick as that of the left. The intraventricular septum was deficient and a glass rod could readily be passed from the right ventricle into the aorta, while a glass rod of finercalibre could be passed into the pulmonary artery. The mitral orifice was normal but the left ventricle was dilated and there was the aforementioned communication with the right ventricle.

Summary. Pulmonary stenosis, deficient intraventricular septum, hypertrophy of the right ventricle, patent foramen ovale, and passive congestion of the viscera.

Case no. 2, M. M. Aged 13. Weight 29 kilos. Height $137 \mathrm{~cm}$. The patient complained that she had had breathlessness, weakness, and blueness of the skin since infancy. On examination she was found to be under-developed, very cyanosed, with pronounced reticular mottling of the skin. The fingers were long and tapering but there was comparatively little clubbing of the tips.

The physical examination was normal except for the circulatory system. The apex beat was in the fifth space, $10 \mathrm{~cm}$. from the mid-sternal line. It was not pronounced on inspection but gave a thudding impression to the palpating finger. There was a palpable systolic thrill in the fourth left space about $7 \frac{1}{2} \mathrm{~cm}$. from the mid-line. The cardiac dullness measured $3 \mathrm{~cm}$. to the right and 11 to the left of the mid-sternal line. The heart sounds were well heard and were accompanied by a harsh systolic murmur heard over all areas but most pronounced in the third left intercostal space about $4 \mathrm{~cm}$. from the mid-line. The second sound of the mitral area was of a slapping character and occasional extrasystoles were detected. The pulse was 115 per minute, easily compressible, with occasional irregularity of the rhythm. On immersing the hand and forearm in hot water the cyanosis practically disappeared. On slight exertion it became intense and although the patient could walk about at a slow pace she had a much greater limit of exertion than case 1, but she could not walk upstairs. The electrocardiograph showed pronounced right-sided preponderance (fig. 2). The examination of the blood showed 
$7,250,000$ red cells, and haemoglobin 145 per cent. The haemotocrit readings showed the corpuscles to occupy 55 per cent by volume and the plasma 45 per cent.

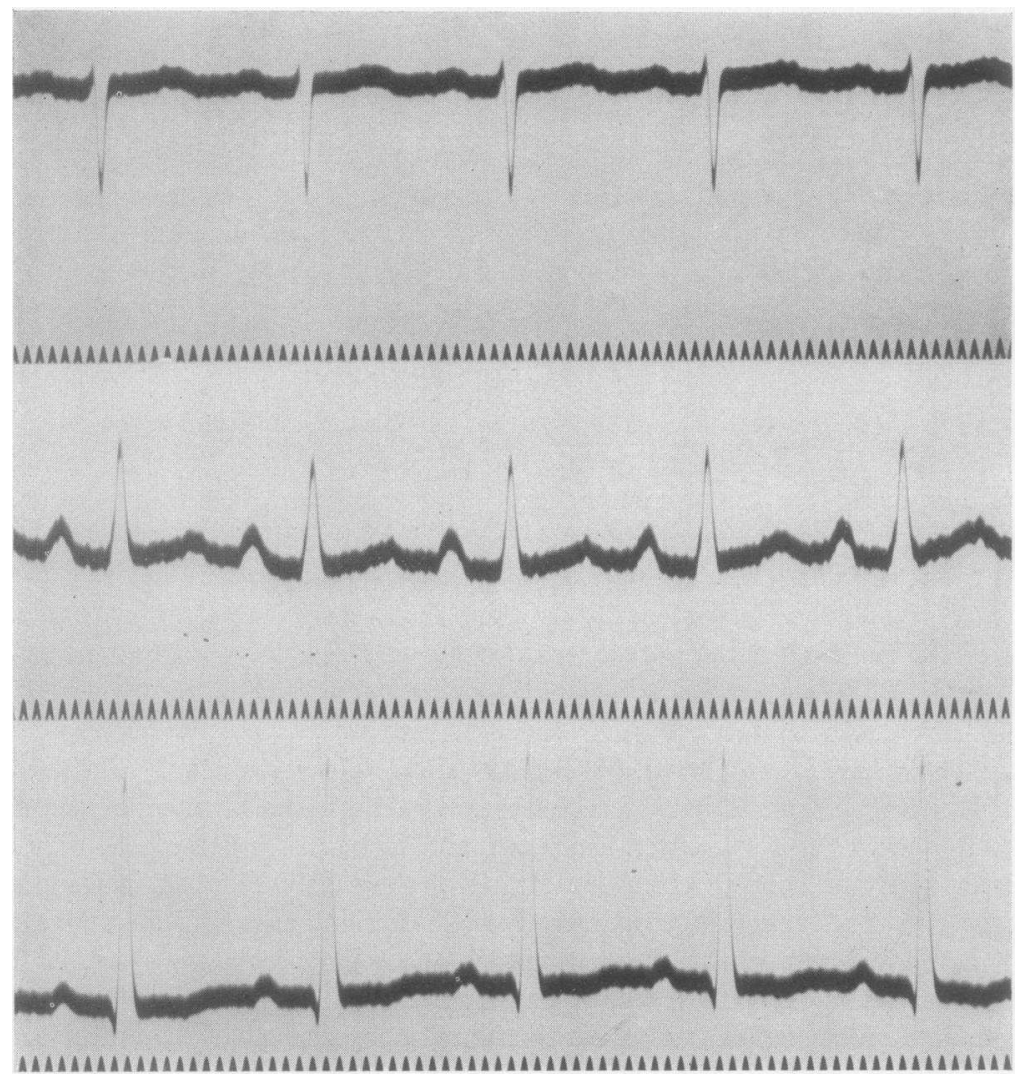

Fig. 2. Regular Rhythm. A-V Conduction time Normal. Right-sided Preponderance of Conǵenital Type with High Voltage. IntraVentricular and Intra-Auricular Conduction Time Normal

"T" wave in Lead III is diphasic, and somewhat flattened in Leads I and II

On the 20th of March, 1928, she was in good physical condition, aged 19 years, apart from breathlessness and cyanosis on exertion.

Case no. 3,F.A. Came under observation at the age of nineteen with a history of cyanosis and dyspnoea on exertion since childhood, and following slight exertion 
he was usually troubled with a cough, although he was able to do some light work. One of his chief complaints was frequent throbbing headaches.

On physical examination there was generalized cyanosis particularly of the face and hands, and pronounced clubbing of the finger tips. Examination of the

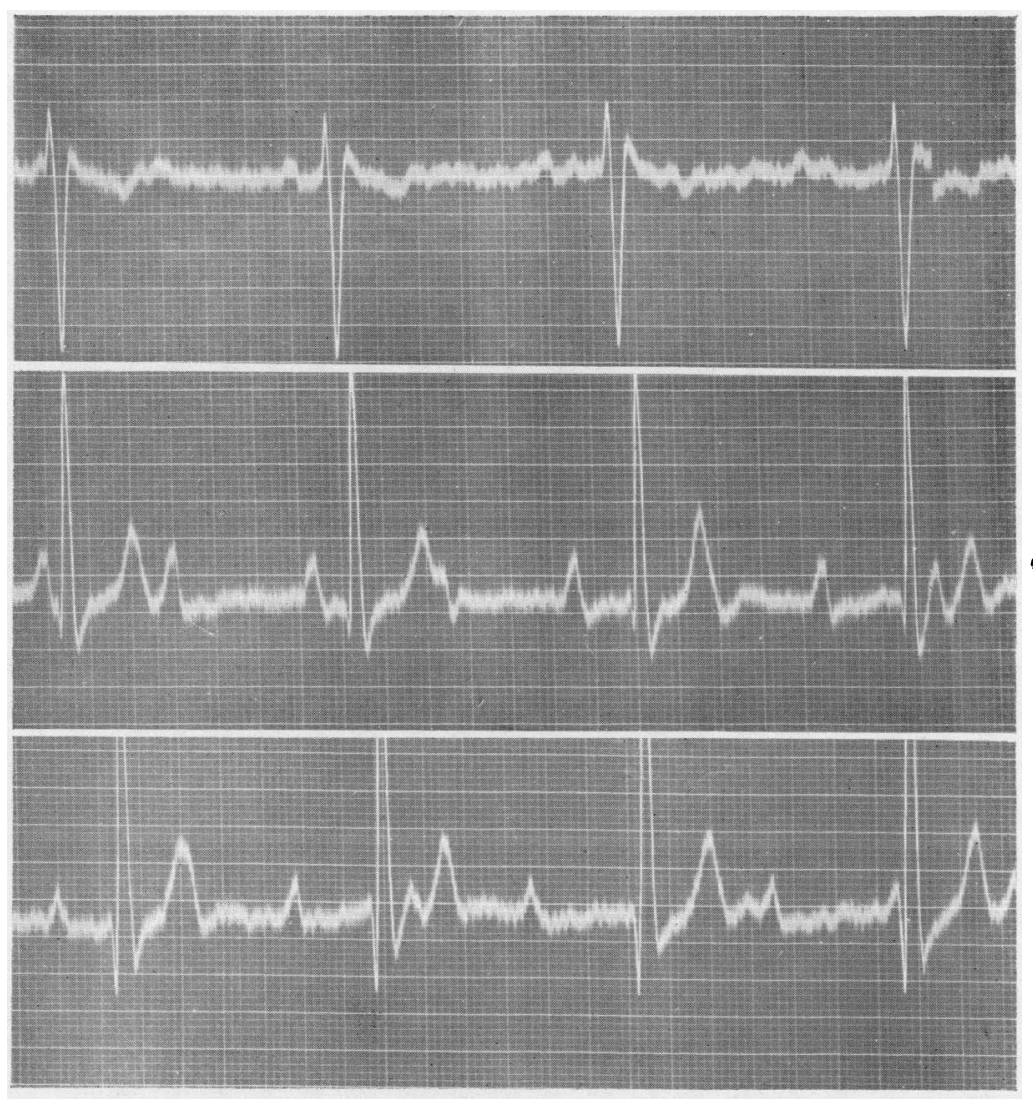

Fig. 3. Complete Heart Block. Right-Sided Preponderance of Congenital Type and High Voltage. Inversion of "T" Wave in Lead I

Ventricular rate -45 . Auricular rate -90.3 m.v. $=3$ c.m.

thorax showed good development with bulging of the praecordium, breathing was rapid, being 40 per minute. The lungs were normal. The cardiac apex beat was in the fifth left interspace $7 \frac{1}{2} \mathrm{~cm}$. from the mid-sternal line. The cardiac dullness was $8 \mathrm{~cm}$. to the left and $3 \mathrm{~cm}$. to the right of the mid-sternal line. No thrills were palpable and no murmurs were audible on auscultation. The pulse 
was 40 per minute, and synchronous with respiration. The systolic blood pressure was $126 \mathrm{~mm}$. and the diastolic $73 \mathrm{~mm}$. The arterial walls were not palpable. The pulsation could be felt in the finger tips. The electrocardiograph showed a right-sided preponderance (fig. 3) and a complete heart block. Examination of the blood showed erythrocytes to be $8,000,000$ and haemoglobin 161 per cent. The haematocrit readings were corpuscles 63 per cent and plasma 37 per cent. An $x$-ray of the chest revealed the heart to be rounder than usual and the aorta to be small.

TABLE 1

Data on cases 1,2 and 3

\begin{tabular}{|c|c|c|c|}
\hline & Case 1 & Case 2 & Case 3 \\
\hline Arterial blood $\mathrm{O}_{2}$ saturation, per cent........... & $63.4^{*}$ & $70 *$ & 81 \\
\hline Arterial blood $\mathrm{CO}_{2}$ content, volumes per cent......... & $28^{*}$ & $33.6^{*}$ & 34.3 \\
\hline Venous blood $\mathrm{O}_{2}$ saturation, per cent $\ldots \ldots \ldots \ldots \ldots$ & 16.5 & 21 & 25.2 \\
\hline $\mathrm{O}_{2}$ Capacity of blood, volumes per cent...... & 32.29 & 27.24 & 29.8 \\
\hline Haemoglobin, per cent.............. & 174 & 147 & 161 \\
\hline \multicolumn{4}{|l|}{ Alveolar air: } \\
\hline $\mathrm{CO}_{2}, m m \ldots$ & 23 & 25.3 & 27 \\
\hline $\mathrm{O}_{2}, m m \ldots \ldots$ & 114 & 116 & 117.5 \\
\hline Expired air, liters per minute. . & 5.03 & 5.26 & 12.82 \\
\hline $\mathrm{CO}_{2}$, per cent............... & 2.12 & 2.07 & 2.05 \\
\hline 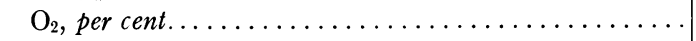 & 18.53 & 17.72 & 18.7 \\
\hline $\mathrm{CO}_{2}$ given up per minute, $c c \ldots \ldots \ldots$ & 96.1 & 139 & 234.6 \\
\hline $\mathrm{O}_{2}$ taken up per minute, $c c \ldots \ldots \ldots \ldots \ldots$ & 114.5 & 178 & 312.8 \\
\hline Respiratory quotient................ & 0.84 & 0.78 & 0.75 \\
\hline Venous $\mathrm{CO}_{2}$ fully oxygenated, $m m \ldots \ldots \ldots \ldots$ & 33 & 33.4 & \\
\hline 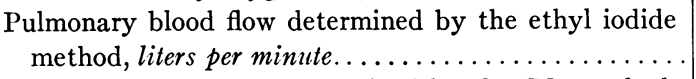 & & & 3.51 \\
\hline 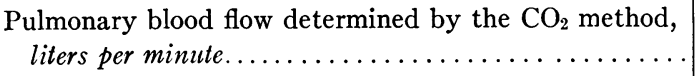 & 1.75 & 2.78 & \\
\hline Pulse rate $\ldots \ldots \ldots \ldots \ldots \ldots \ldots \ldots \ldots \ldots$ & 108 & 100 & 40 \\
\hline
\end{tabular}

* The exact accuracy of these findings is open to doubt on account of the great difficulty in obtaining even small amounts of arterial blood.

\section{RESPIRATORY FUNCTION}

The respiratory rate and rhythm in cases 1 and 2 were within normal limits. In case 3 , however, over a long period of observation it has been found that the respiratory rate synchronizes with that of the heart rate. An adequate explanation of this phenomenon has not been discoverable. This rapid respiratory rate is reflected in the large minute volume of expired air in this case. It amounted to 12.82 
liters per minute. The details of the respiratory and blood gas data are set forth in table 1.

\section{CARBON DIOXIDE DISSOCIATION CURVES}

The carbon dioxide dissociation curves in all cases showed a pronounced lowering as seen in figures 4,5 , and 6 . On plotting the partial

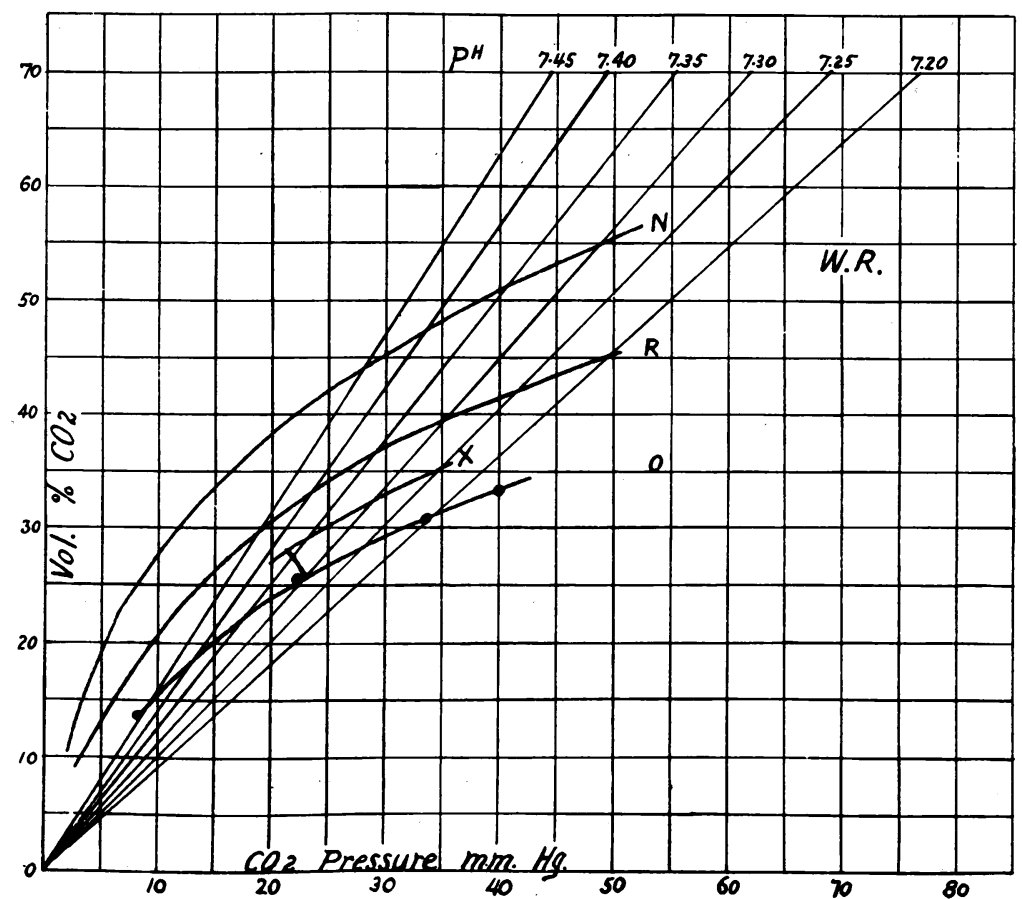

Fig. 4. Carbon Dioxide Dissociation Curves of Case 1

$N$-normal fully oxygenated $\mathrm{CO}_{2}$ curve, $R$-fully reduced $\mathrm{CO}_{2}$ curve, $O$-fully oxygenated $\mathrm{CO}_{2}$ curve, $\mathrm{X}-\mathrm{CO}_{2}$ curve at an oxygen saturation as found in the arterial blood.

pressure of $\mathrm{CO}_{2}$ of the alveolar air on the curve of the fully oxygenated blood (as it might be presumed to be as it left the lungs) it is found that the $\mathrm{CO}_{2}$ content of such blood was $25.5 \mathrm{cc}$. volumes per cent in case 1 , $30.5 \mathrm{cc}$. volumes per cent in case 2 , and $33.5 \mathrm{cc}$. volumes per cent in case 3. But the $\mathrm{CO}_{2}$ content of the radial blood was definitely greater in each case as follows: 


\begin{tabular}{c|c|c}
\hline Case & $\begin{array}{c}\mathrm{CO}_{2} \text { content, cc. volumes per cent } \\
\text { in pulmonary blood }\end{array}$ & $\begin{array}{c}\mathrm{CO}_{2} \text { content, cc. volumes per cent } \\
\text { in radial blood }\end{array}$ \\
\hline 1 & 25.5 & 28.0 \\
2 & 30.5 & 33.6 \\
3 & 33.5 & 34.3 \\
\hline
\end{tabular}

The elevation of the dissociation curve however produces a lowering of partial pressure of the $\mathrm{CO}_{2}$ in arterial blood although the content is increased.

\begin{tabular}{c|c|c}
\hline Case & $\begin{array}{c}\text { Partial pressure of } \mathrm{CO}_{2} \text { in the } \\
\text { pulmonary blood }\end{array}$ & $\begin{array}{c}\text { Partial pressure of } \mathrm{CO}_{2} \text { in the } \\
\text { radial blood }\end{array}$ \\
\cline { 2 - 2 } 1 & mm. Hg. & mm. Hg. \\
23 & 21 \\
3 & 25.3 & 23.5 \\
27 & 26 \\
\hline
\end{tabular}

If a similar comparison be made of the $\mathrm{pH}$ of the pulmonary and radial it will be found that there is a distinct shift towards alkalinity in the latter.

\begin{tabular}{c|c|c}
\hline $\mathrm{CO}_{2}$ & $\mathrm{pH}$ of the pulmonary blood & $\mathrm{pH}$ of the radial blood \\
\hline 1 & 7.30 & 7.37 \\
2 & 7.36 & 7.40 \\
3 & 7.35 & 7.37 \\
\hline
\end{tabular}

The sum total of these findings would indicate that there had been an efficient attempt to compensate for the disturbed aeration of the arterial blood.

\section{THE OXY-HAEMOGLOBIN DISSOCIATION CURVES}

The oxy-haemoglobin dissociation curves (figs. 7, 8 and 9) show in all cases a distinct shift to the left, as would be expected if an alkalosis were present. These curves are similar to those found by the Royal Society Expedition to the Andes (1) and conform to the oxy-haemoglobin curves which Barcroft (2) found to occur when the haemoglobin was concentrated in human blood. It may also be noted that the $\mathrm{CO}_{2}$ curves are of a sim:lar character to those found by this Expe- 
dition. When the findings of the blood gases in the arterial blood of those suffering from mountain sickness and these cases of congenital heart disease are compared, the similarity is most striking. In the cases here reported the oxygen saturation of the arterial blood was 63.4

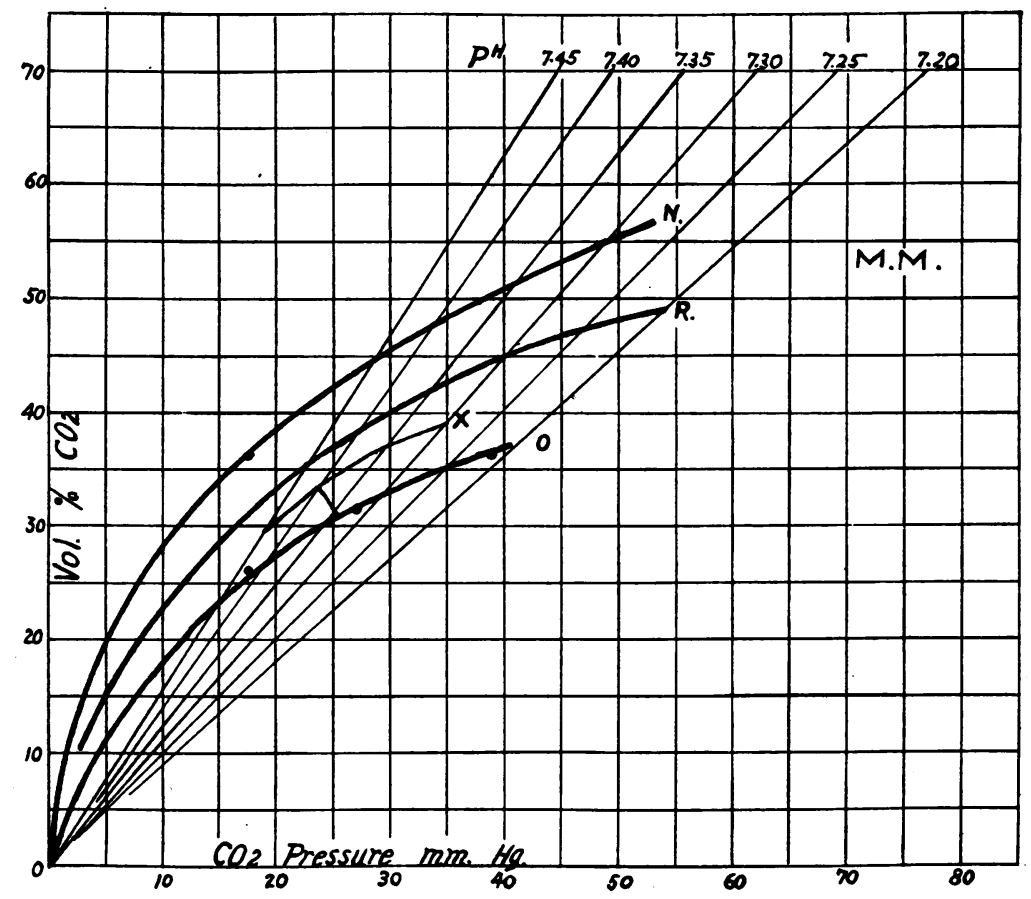

Fig. 5. Carbon Dioxide Dissociation Curves of Case 2

$N$-normal oxygenated $\mathrm{CO}_{2}$ curve, $R$-fully reduced $\mathrm{CO}_{2}$ curve, $O$-fully oxygenated $\mathrm{CO}_{2}$ curve, $\mathrm{X}-\mathrm{CO}_{2}$ curve at an oxygen saturation as found in the arterial blood.

per cent in case 1,70 per cent in case 2 , and 81 per cent in case 3 , while the $\mathrm{CO}_{2}$ content was respectively $28 \mathrm{cc}$., $33.6 \mathrm{cc}$. and $34.3 \mathrm{cc}$., volumes per cent. In these cases the degree of oxygen de-saturation of the arterial blood was greater than that found in any people living at high altitudes. 


\section{RIGHT TO LEFT SHUNT IN THE HEART}

A number of attempts have been made to determine the amount of blood diverted from the right heart into the main arterial circulation through abnormal communications. The premises upon which calculations of the right to left shunt have been made were as follows: (1)

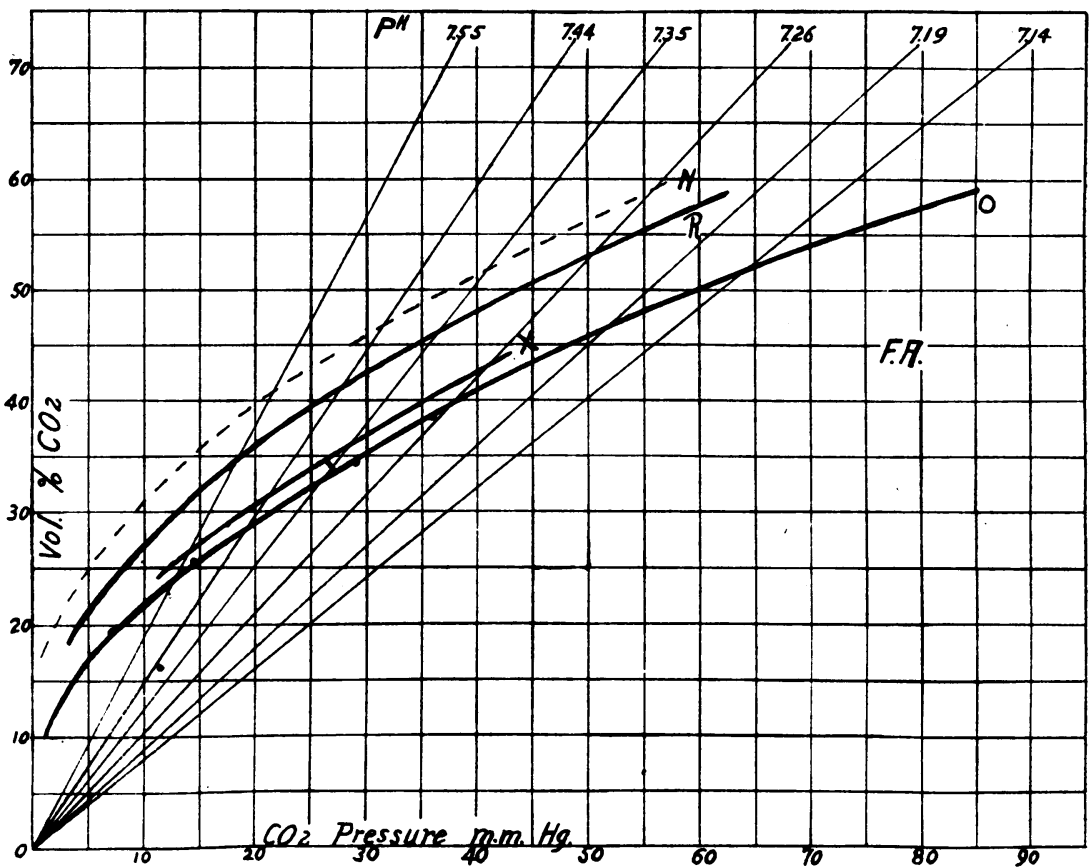

Fig. 6. Carbon Dioxide Dissociation Curves of Case 3

$N$-normal oxygenated $\mathrm{CO}_{2}$ curve, $O$-fully oxygenated $\mathrm{CO}_{2}$ curve, $R$-fully reduced $\mathrm{CO}_{2}$ curve, $X-\mathrm{CO}_{2}$ curve at an oxygen saturation as found in the arterial. blood.

the minute volume blood flow through the lungs; (2) the oxygen consumption per minute; (3) the oxygen content of the arterial blood; (4) the oxygen content of the blood leaving the lungs which was taken to be 95.5 per cent saturated; (5) the oxygen content of the venous blood was then either indirectly estimated by subtracting from the oxygen content of the blood leaving the lungs the amount calculated as being taken. 


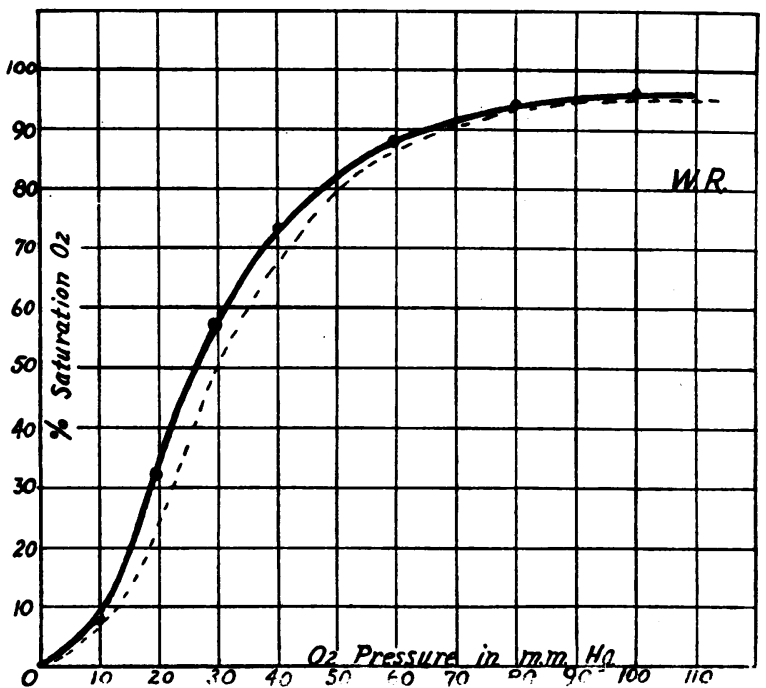

Fig. 7. Oxy-Haemoglobin Dissociation Curve of Case 1 Solid line that of patient, dotted line that of normal

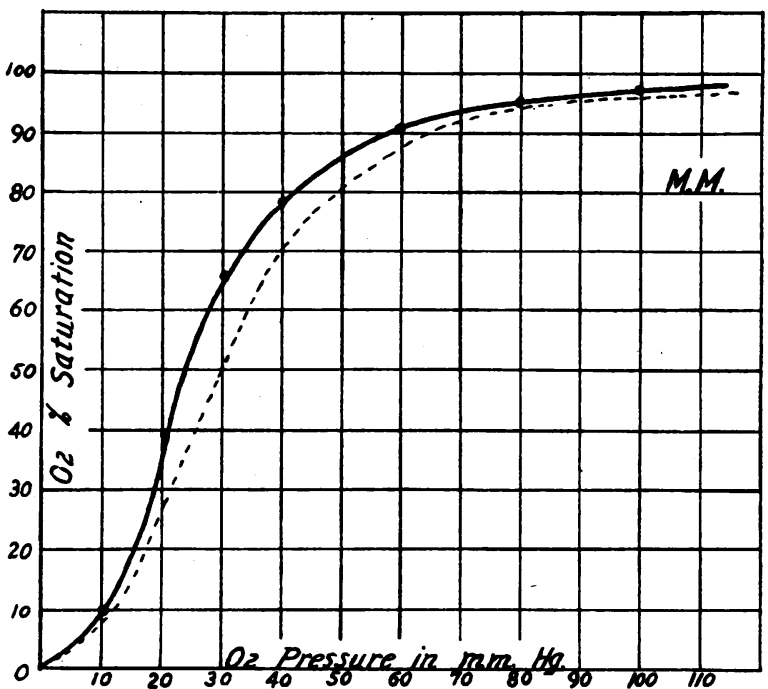

Fig. 8. Oxy-Haemogiobin Dissociation Curve of Case 2 Solid line that of patient, dotted line that of normal 


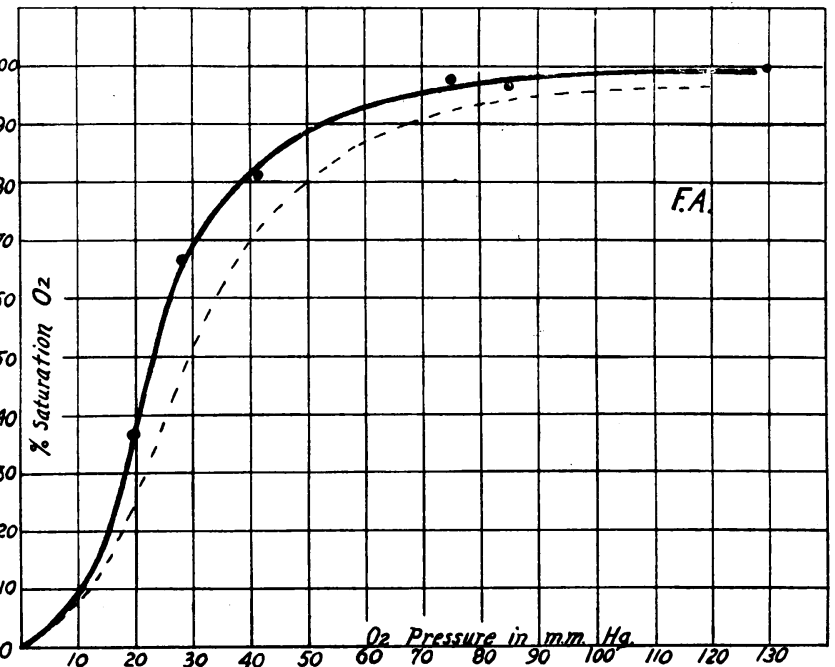

Fig. 9. Oxy-Haemoglobin Dissociation Curve of Case 3

Solid line that of patient, dotted line that of normal

TABLE 2

Venous shunt in case 3 using the method of Weiss and Lowbeer

$\mathrm{O}_{2}$ capacity of blood from radial artery $=29.8 \mathrm{cc}$. volumes per cent.

$\mathrm{O}_{2}$ content of pulmonary blood leaving lungs $=29.8 \times 95.5=28.45 \mathrm{cc}$. volumes per cent. $\mathrm{O}_{2}$ consumption per minute (B.M.R.) $=234.6 \mathrm{cc}$.

Lung flow determined by ethyl iodid method $=3.51$ liters per minute.

$\mathrm{O}_{2}$ intake by lungs $=\frac{234.6}{3.51}=66.8 \mathrm{cc}$. per liter of blood.

$\mathrm{O}_{2}$ content of blood in radial artery $=24.3 \mathrm{cc}$. volumes per cent.

$\mathrm{O}_{2}$ content of mixed venous blood $=28.45-6.68=21.77$ cc. volumes per cent.

Let $X=$ the venous shunt in liters.

Total blood flow $=3.51+X$ liters.

(A) Total $\mathrm{O}_{2}$ in mixed arterial blood $=(3.51+X) 24.3 \times 10$

(B) Total $\mathrm{O}_{2}$ in circulation

$$
=(3.51 \times 28.45+21.77 X) 10
$$

$\therefore \mathrm{A}=\mathrm{B}$

$$
\begin{aligned}
(3.51+X) 24.3 \times 10 & =(3.51 \times 28.45+21.77 X) 10 \\
25.3 X & =147 \\
X & =5.82 \text { liters per minute } \\
5.82+3.51 & =9.33 \text { liters total flow per minute } \\
(5.82 \div 9.33) 100 & =62.4 \text { per cent venous shunt }
\end{aligned}
$$


TABLE 3

Venous shunt in case 3 calculated by using Lundsgaard's figure for oxygen consumption in the tissues ( 5 volumes per cent)

$\mathrm{O}_{2}$ capacity in radial artery $\quad=29.8 \mathrm{cc}$. volumes per cent

$\mathrm{O}_{2}$ content in pulmonary vein blood $=29.8 \times 95.5$ per cent $=28.45 \mathrm{cc}$. volumes per cent

$\mathrm{O}_{2}$ content in radial artery $\quad=24.3 \mathrm{cc}$. volumes per cent

$\mathrm{O}_{2}$ in venous blood $=24.3-5=19.3 \mathrm{cc}$. volumes per cent

Let $X=$ the venous shunt in percentage of the total blood flow,

$100-X=$ the percentage amount of blood entering the arterial system from the pulmonary veins,

$\therefore \mathrm{O}_{2}$ in radial artery blood $=\frac{\text { Venous } \mathrm{O}_{2} X}{100}+\frac{\mathrm{O}_{2} \text { in pulmonary veins }}{100}(100-X)$ (volumes per cent)

$$
\begin{aligned}
24.3 & =\frac{19.3 X}{100}+\frac{28.45(100-X)}{100} \\
2430 & =19.3 X+2845-28.45 X \\
X & =45.4 \text { per cent venous shunt }
\end{aligned}
$$

TABLE 4

Venous shunt in case 3 calculated by using the oxygen content of blood of the arm vein as representing that in the right auricle

$\mathrm{O}_{2}$ capacity in radial artery $\quad=29.8 \mathrm{cc}$. volumes per cent

$\mathrm{O}_{2}$ content in pulmonary vein blood $=29.8 \times 95.5$ per cent $=28.45 \mathrm{cc}$. volumes per cent

$\mathrm{O}_{2}$ content in radial artery

$=24.3 \mathrm{cc}$. volumes per cent

$\mathrm{O}_{2}$ content in arm vein $\quad=7.5 \mathrm{cc}$. volumes per cent

Let $X=$ the venous shunt in percentage of the whole blood flow,

$\therefore \mathrm{O}_{2}$ in radial artery $=\frac{\text { Venous } \mathrm{O}_{2} \times X}{100}+\frac{\mathrm{O}_{2} \text { in pulmonary veins }}{100}(100-X)$

(cc. volumes per cent)

$$
\begin{aligned}
24.3 & =\frac{7.5 X}{100}+\frac{29.45(100-X)}{100} \\
2430 & =7.5 X+2845-28.45 X \\
20.9 X & =415 \\
X & =19.85 \text { per cent venous shunt }
\end{aligned}
$$

TABLE 5

Comparison of three methods of calculating venous shunt

\begin{tabular}{c|c|c|c}
\hline Case & $\begin{array}{c}\text { Venous shunt calculated } \\
\text { by the Weiss-Lowber } \\
\text { method }\end{array}$ & $\begin{array}{c}\text { Venous shunt calculated } \\
\text { by substracting 5 cc. } \\
\text { volumes per cent of oxygen } \\
\text { from the radial blood O2 } \\
\text { content for the venous } \\
\text { blood }\end{array}$ & $\begin{array}{c}\text { Venous shunt calculated } \\
\text { by using the } \text { O2 }_{2} \text { content } \\
\text { of the arm vein blood as } \\
\text { representing the general } \\
\text { venous blood }\end{array}$ \\
\hline 1 & per cent shunt & per cent shunt & per cent shunt \\
2 & $\begin{array}{c}\text { Negative } \\
\text { Negative }\end{array}$ & 68.8 & 40.5 \\
3 & 62.4 & 58 & 34 \\
& & 45.4 & 19.8 \\
\hline
\end{tabular}


up per $100 \mathrm{cc}$. of blood passing through the lungs, i.e., $\mathrm{O}_{2}$ content of blood leaving the lungs minus $\frac{\text { oxygen consumption in cc. }}{\text { blood flow in liters }} \times \frac{1}{10}$ or the oxygen content of the blood in the peripheral veins was taken as representative of the blood entering the lungs, - or a theoretical $5 \mathrm{cc}$. volumes per cent of oxygen was subtracted from the oxygen content in the arterial blood, the result being considered to represent that of the mixed venous blood entering the lungs. Further, it was always taken as a definite fact that the blood entering the lungs was the same as that entering the right auricle and that there was no enrichment of the venous blood by mixing with the oxygenated blood in the left ventricle. In other words, it was considered that the diversion of blood occurred only from the right to the left ventricle during systole of the heart and that during cardiac diastole no contrary mixing occurred.

The manner of procedure and the results obtained in case 3 by three different methods of calculation are shown in tables 2,3 , and 4 , while in table 5 is given a comparison of the results of right to left shunt in all of the cases.

It would seem impossible therefore to determine the venous shunt in such cases of congenital heart disease by these modified aerotonometric methods.

\section{CONCLUSIONS}

1. There is a distinct decrease in the oxygen saturation of the arterial blood.

2. There is an increase in the $\mathrm{CO}_{2}$ content and a decrease in the $\mathrm{CO}_{2}$ partial pressure in the arterial blood as compared with the pulmonary blood leaving the lungs.

3. There is a pronounced shift of the $\mathrm{CO}_{2}$ dissociation curve towards the right in such cases.

4. The $\mathrm{pH}$ of the arterial blood is more alkaline than the blood leaving the lungs.

5. It was found impossible to obtain reliable determinations of the venous or right to left shunt in these cases. 


\section{BIBLIOGRAPHY}

1. Barcroft, J., and Others, Philos. Trans. Roy. Soc., Series B, 1922, ccxi, 377. Observations upon the Effect of High Altitude on the Physiological Processes of the Human Body, carried out in the Peruvian Andes, chiefly at Cerro de Pasco.

2. Barcroft, J., and Murray, C. D. Philos. Trans. Roy. Soc., Series B, 1922, ccxi, 469. Some Secondary Effects of Increasing the Proportion of Red Corpuscles in Blood.

3. Weiss, R., and Lowbeer, B. Wien. Arch. f. inn. Med. 1923, vii, 381. Untersuchungen über einen Fall von kongenitalem Herzvitium. II. Gasanalytische Untersuchungen. 